$\stackrel{W}{=}$

Global journals Inc.

(2)

\title{
Prevalence, Pattern and Impact of Self Medication of Anti- Infective Agents during COVID-19 Outbreak in Dhaka City
}

\section{By Nasir M, Mannan M, Chowdhury ASM, Zahan T \& Perveen RA}

Abstract-Background: The outbreak of coronavirus disease-2019 is putting a massive strain on the vulnerable healthcare systems in low and middle-income countries like Bangladesh. Inequitable access to healthcare is further widened by the socio-economic gap and sense of insecurity during this pandemic. Self-medication is a common practice in Bangladesh as it provides a low-cost alternative for people, which involves inappropriate and injudicious use of medicines to treat self-recognized symptoms by the people. During the outbreak of COVID-19 in Dhaka city, the tendency of taking medicines by own decision was increased alarmingly due to unusual distress, caused by high self-awareness of their health and buying capacity of medication.

Objectives: To observe the prevalence, pattern, sources, and impact of self-medication practice among the respondents with high socio-economic standings and education.

Setting: Citizens living in Dhaka city, Bangladesh, during the COVID-19 outbreak from April 2020 to May 2020. Method: Cross-sectional online survey conducted on 626 citizens without having a background of medical knowledge or related to any healthcare services (doctors, nurses, pharmacists, medical students) by structured questionnaires during the COVID-19 outbreak.

Outcome measures: Frequency of self-medication, commonly used antimicrobial agents, symptoms causing self-medication, sources of inspiration, relation with COVID-19 test results, economic burden involved in self-medication during the outbreak.

\section{GJMR-B Classification: NLMC Code: QW 4}

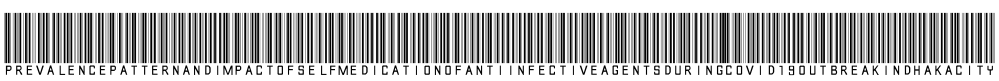

Strictly as per the compliance and regulations of:

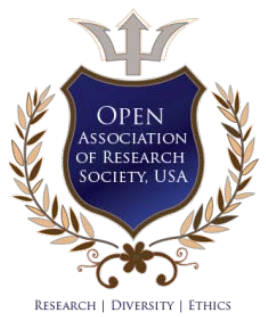

(C) 2020. Nasir M, Mannan M, Chowdhury ASM, Zahan T \& Perveen RA. This is a research/review paper, distributed under the terms of the Creative Commons Attribution-Noncommercial 3.0 Unported License http://creativecommons.org/licenses/by$\mathrm{nc} / 3.0 /$ ), permitting all non-commercial use, distribution, and reproduction in any medium, provided the original work is properly cited. 


\title{
Prevalence, Pattern and Impact of Self Medication of Anti-Infective Agents during COVID-19 Outbreak in Dhaka City
}

\author{
Nasir $\mathrm{M}^{\alpha}$, Mannan $\mathrm{M}^{\sigma}$, Chowdhury $\mathrm{ASM}^{\circ}$, Zahan $\mathrm{T}^{\omega}$ \& Perveen RA
}

Abstract-Background: The outbreak of coronavirus disease2019 is putting a massive strain on the vulnerable healthcare systems in low and middle-income countries like Bangladesh. Inequitable access to healthcare is further widened by the socio-economic gap and sense of insecurity during this pandemic. Self-medication is a common practice in Bangladesh as it provides a low-cost alternative for people, which involves inappropriate and injudicious use of medicines to treat self-recognized symptoms by the people. During the outbreak of COVID-19 in Dhaka city, the tendency of taking medicines by own decision was increased alarmingly due to unusual distress, caused by high self-awareness of their health and buying capacity of medication.

Objectives: To observe the prevalence, pattern, sources, and impact of self-medication practice among the respondents with high socio-economic standings and education.

Setting: Citizens living in Dhaka city, Bangladesh, during the COVID-19 outbreak from April 2020 to May 2020. Method: Cross-sectional online survey conducted on 626 citizens without having a background of medical knowledge or related to any healthcare services (doctors, nurses, pharmacists, medical students) by structured questionnaires during the COVID-19 outbreak.

Outcome measures: Frequency of self-medication, commonly used antimicrobial agents, symptoms causing self-medication, sources of inspiration, relation with COVID-19 test results, economic burden involved in self-medication during the outbreak.

Results: The prevalence of self-medication amid the pandemic of the COVID-19 was $88.33 \%$, and only 179 (28.59\%) took medication with doctors' advice and the remaining 447 (71.40\%) respondents took the drugs as "self-medication" by other sources. The most frequently used anti-infective drugs during the outbreak were ivermectin $(77.15 \%)$, azithromycin (54.15\%), doxycycline (40.25\%). The common symptoms were fever, throat pain, dry-cough, and a total 105 (16.77\%) respondents took medications without having any symptoms. Almost 355 (85.33\%) had taken medication without doing any test for COVID-19. The causes of self-medication as news of spread, effects, and remedies in media channels, internet, mental stress of lockdown and isolation, insecurity, and panic about the scarcity of drug and healthcare support.

\footnotetext{
Corresponding author a: Professor and Head of Pharmacology, Holy Family Red Crescent Medical College, Dhaka, Bangladesh.

e-mail: morshednasir@hotmail.com

Author o: Student in Applied Clinical Research Program, McMaster University, Toronto, Canada. e-mail: mannanmahmudul@gmail.com

Author p: Lecturer of Pharmacology, Holy Family Red Crescent Medical College, Dhaka, Bangladesh. e-mail: saber.ac4321@gmail.com

Author $\omega ¥$ : Assistant Professor of Pharmacology, Holy Family Red Crescent Medical College, Dhaka, Bangladesh.

e-mails: tahminazahan@yahoo.com, rawshanperveen@gmail.com
}

Conclusion: High risks of developing antibiotic resistance, adverse drug reactions, and financial loss were predictable with the absence of strict regulatory enforcement to protect people and proper utilization resources during the COVID-19 outbreak in Dhaka city.

\section{IMPACT ON PRACTICE}

- Self-medication of anti-infective agents during the COVID-19 outbreak is high due to inadequate access to the doctors, easy availability of any drugs without prescription, and remedy of common symptoms.

- Most of the educated citizens having high socioeconomic status in Dhaka become stressed due to scarcity of supply as informed by news media, internet, and friends that provoked self-medication of anti-infective agents.

- Unapproved medications for the COVID-19 like azithromycin, doxycycline, hydroxychloroquine and ivermectin were used in self-medication that added unnecessary financial burden.

- Lack of monitoring, surveillance, and regulations in drug dispensing can be a major cause of resistance, organ damage, adverse drug reactions, and interrupted supply chain for high demand during the COVID-19 outbreak in Dhaka city.

\section{INTRODUCTION}

$\Lambda$ ccording to the World Health Organization (WHO), self-medication is explained as "the selection and use of medicines by individuals (or a member of the individual's family) to treat self-recognized or selfdiagnosed conditions or symptoms. Reasons commonly adducted for indulgence in self-medication include delayed access to healthcare centers, socio-cultural belief, relatively high cost of hospital treatment, previous experience of treatment of same symptoms, easy availability of drugs, poor regulatory practice, the urgency of feeling relieved, advice from friends and media. The of self-medication is prevalent in most parts of Bangladesh, regardless of socio-economic status and level of education. While this is indisputable, the incidence of self- medication is may be higher in the low or middle-income countries without consulting with qualified health professionals ${ }^{1}$. Although the $\mathrm{WHO}$ stressed that rational self-medication practice helps in 
the prevention and treatment of some minor pathological conditions at affordable cost ${ }^{2}$, otherwise it may cause wastage of resources, resistance to pathogens, and serious health hazards with adverse drug reactions and prolonged morbidity ${ }^{3}$. In a developing country like Bangladesh, the practice of selfmedication may provide an alternative for people as lowcost to avoid the high cost of clinical services, and many drugs dispensed over the counter (OTC) without prescription ${ }^{4}$. But it is gone beyond the OTC drugs and sometimes prescription-only drugs like antimicrobials, sedatives, hypnotics and strong NSAIDs also reported to be dispensed without prescription in few cases.

Moreover, the ratio between doctor and patient in Bangladesh is currently as low that places the country at second position from the bottom, among the South Asian countries, according to the $\mathrm{WHO}^{5}$. Besides, some individuals practice out of ignorance, poverty, and generalized hypes.

Dhaka, being the capital and the major economic-hub of the country; it lags in the ratio between healthcare workers compared to other neighboring countries, thus hampering proper and timely healthcare. So, practice of self-medication is almost inevitable as the country has only six doctors, nurses, and midwives for every 10,000 populations, according to the report of health bulletin published yearly by the Health Ministry ${ }^{6}$. Some studies on the general tendency and pattern of self-medication practice of prescription-only drugs among students, and people with or without medical knowledge showed an alarming scenario in Dhaka city ${ }^{7}$.

The outbreak of coronavirus disease-2019 is putting a massive strain on vulnerable healthcare systems in low and middle-income countries like Bangladesh. Inequitable access to healthcare is further widened by the socio-economic gap and sense of insecurity during this pandemic since the beginning of $2020^{8}$. Besides, the population of higher socioeconomic standing is more potential to have access to better health information, medications and affordability that may lead to self-medication practice in mass. Similarly, people with higher education are reported to have much distress, probably due to high selfawareness and access to mass information network ${ }^{9}$.

The combat against COVID-19 is continuing in Bangladesh, with the highest incidence rate in Dhaka city. The available data by $\mathrm{WHO}$ revealed that the highest AR was observed to continue in the Dhaka $(2321.7 / 1,000,000)$ and was highest $(9422.1 / 1,000,000)$ from April to June $2020^{10}$. As there is no approved cure for the COVID-19 or a vaccine against SARS-CoV-2, the aim of treatment is focused to manage and reduce symptoms until clinical recovery. Most people (around $80 \%$ ) are an asymptomatic or mild infections that can be treated at home.

As stated in the National Guideline on Case Management of COVID-19 in Bangladesh, there is no precise, effective treatment for COVID-19; the mainstay of management is early diagnosis and supportive care of symptoms and optimum support for organ function in severe illness. No drug is yet recommended as chemoprophylaxis as there is no quality evidence of efficacy and safety in COVID 19. Though Patients should be managed in hospital settings; however, proper home care may also be advised with mild illness unless rapid deterioration or inability to avail hospital if necessary ${ }^{11}$. But lack of rapid response, scarcity of hospital beds, absence of private practice, inadequate capacity of testing (RT-PCR), the spread of un-authenticated treatment protocols are putting the citizens in the dilemma of choosing medical advice. Lot of prescription-only drugs like antimicrobials (azithromycin, doxycycline), anti-parasitic (ivermectin), anti-malarial (hydroxychloroquine) are reported to become a shortage in the dispensary and peripheral supply chain throughout the city. Moreover, the risk of a wide range of side effects (Table-I) are also of great concern for undocumented self-medication.

Table-l: List of possible side effects of anti-infective agents used in self-medication during COVID-19

\begin{tabular}{|c|c|c|}
\hline & Mild / common & Severe / rare \\
\hline Azithromycin & $\begin{array}{l}\text { Diarrhea, nausea, abdominal pain, vomiting, } \\
\text { headache }\end{array}$ & $\begin{array}{l}\text { Prolong QT interval, Arrhythmia, Hepatic } \\
\text { dysfunction, Myasthania }\end{array}$ \\
\hline Doxycycline & $\begin{array}{l}\text { loss of appetite, nausea, vomiting, diarrhea, } \\
\text { rash, sensitivity to the sun, hives, discoloring } \\
\text { of teeth, bloody diarrhea, stomach cramping } \\
\text { and pain, fever, dehydration, weight loss }\end{array}$ & $\begin{array}{l}\text { headache, blurry vision, double vision, vision } \\
\text { loss, Irritation of esophagus, Anemia, } \\
\text { Pancreatitis. pain in upper abdomen, fever, } \\
\text { skin reactions, blisters, peeling skin, small } \\
\text { purple spots }\end{array}$ \\
\hline Hydroxychloroquine & $\begin{array}{l}\text { nausea, vomiting, stomach pain or cramps, } \\
\text { loss of appetite, weight loss, diarrhea, } \\
\text { dizziness, spinning sensation, headache, } \\
\text { ringing in ears, mood changes, } \\
\text { nervousness, irritability, skin rash, itching, or } \\
\text { hair loss. }\end{array}$ & $\begin{array}{l}\text { Bone marrow depression, anemia, aplastic } \\
\text { anemia, agranulocytosis, leukopenia, and } \\
\text { thrombocytopenia. Hemolysis reported in } \\
\text { individuals with glucose-6- phosphate } \\
\text { dehydrogenase deficiency, Cardiomyopathy, } \\
\text { cardiac failure, prolongs the QT interval, } \\
\text { Ventricular arrhythmias, torsade de pointes }\end{array}$ \\
\hline
\end{tabular}




\begin{tabular}{|l|l|l|}
\hline Ivermectin & $\begin{array}{l}\text { tiredness, loss of energy, stomach pain, loss } \\
\text { of appetite, nausea, vomiting, diarrhea, } \\
\text { dizziness, sleepiness or drowsiness, } \\
\text { itchiness, trouble breathing, swelling of } \\
\text { throat or tongue, skin rash }\end{array}$ & . \\
\hline
\end{tabular}

Because of commonly occurring symptoms of soreness or pain in throat, dry cough, fever, body ache, breathlessness, people started to take medicines without being diagnosed or tested for COVID-19. Besides the risk of misuse or overuse of these drugs may lead to immediate or delayed complications including adverse drug reactions (hypersensitivity, anaphylaxis), drug interactions, malfunction or destruction of vital organs such as the liver, kidney; the practice of self-medication gives a deceitful sense of security, and masking the correct diagnosis. Many countries are using different drugs, but they are not using those as the guidelines and should only be used under the supervision of physicians on a case-by-case basis, not as a general recommendation ${ }^{12}$.

Given this high prevalence of self-medication of prescription-only drugs in Bangladesh and its associated adverse socio-economic impact on individuals, and the healthcare service system, supply chain at large. This study is therefore done to evaluate the awareness, pattern and attitude towards selfmedication of anti-infective agents among the high socio-economic and educated citizens in Dhaka during the outbreak of the COVID-19 without testing, diagnosis and prescription.

Ethics Approval: None of the authors has any conflict including employment, consultancies, stock ownership, honoraria, paid expert testimony, patent applications/ registrations for this study.

\section{il. Methodology}

Using and relying on the authors' network with people living in Dhaka city, the capital of Bangladesh; this online survey adopted a descriptive nonexperimental research design to investigate the awareness and practice of self-medication conducted from April to June 2020, the period during the nationwide lockdown and to surge of number of positive COVID-19 cases. Because it was not feasible to do a community-based sampling survey during this outbreak period, we decided to collect data online by convenience sampling. A structured questionnaire was circulated to complete via clicking the link, connected to Google form. The questionnaire contained a brief introduction on the background, objective, procedure, voluntary nature of participation, declaration of anonymity and confidentiality, and notes for filling in the online questionnaire.

The online questionnaire was developed and validated through the face and content validity techniques, by giving the draft questionnaire to a few of the citizens with inclusion criteria at Dhaka city, to assess whether the response looks meaningful, well designed and a good measure of the construct to an innocent bystander. The response was used to refine and modify the questionnaire further.

The content validity was done by giving the resultant questionnaire to three independent scholars from the fields of Public Health, Pharmacology, and Social Statistics to assess its appropriateness, clarity, coverage, and relevance to the study.

The reliability of the validated questionnaire was ascertained by test-retest method. The questionnaire was administered twice at two weeks' interval on ten respondents from Dhaka city who practiced selfmedication during the COVID-19 outbreak. The responses were compared and the reliability coefficient determined $(r=0.83)$. The incorporated draft questionnaire was recast for ambiguity and repetitive questions were struck off.

The cross sectional populations were included with the inclusion criteria as, the adult citizens living in Dhaka city, aged 25 years or more, with the education level of graduation or above, non-medical professionals, having email address, and agreed to participate voluntarily. Respondents having involvement or knowledge on medical background (medical graduates, medical practitioners, nurses, medical researchers, pharmacists) were excluded from finding out the public perceptions, and their responses to take medications without prescription during the COVID-19 outbreak. The frequencies of the response were recorded in the datasheet, and observed according to demographic characteristics, sources of information, clinical symptoms, the status of COVID-19 test results, and cost involvement. The market prices of commonly used medicines as self-medication during the outbreak were calculated to reveal the economic burden caused by COVID-19 driven self-medication practice.

\section{Results}

Total of 639 participants completed the online survey questionnaire and submitted it with e-mail verification. After excluding 13 respondents, of whom 10 were doctors by profession and three were below the minimum age limit (25 years), the final sample consisted of 626 were valid participants. Among the final sample, $316(50.47 \%)$ respondents were from the age group of 45-54 years, 346 (55.27\%) were women, 312 (49.84\%) held a bachelor's degree, and 230 (36.74\%) engaged in non-civil services. Other demographic characteristics are shown in Table-II. 
Table-Il: Frequency distribution of respondents by their socio-demographic features

\begin{tabular}{|c|c|c|}
\hline Variables & Frequency & Percentage (\%) \\
\hline \multicolumn{3}{|c|}{ Gender: } \\
\hline Male & 282 & $45.04 \%$ \\
\hline Female & 346 & $55.27 \%$ \\
\hline \multicolumn{3}{|c|}{ Age: } \\
\hline $25-34$ & 96 & $15.33 \%$ \\
\hline $35-44$ & 156 & $24.92 \%$ \\
\hline $45-54$ & 316 & $50.47 \%$ \\
\hline $55+$ & 58 & $9.26 \%$ \\
\hline \multicolumn{3}{|c|}{ Education level: } \\
\hline Undergraduate & 110 & $17.57 \%$ \\
\hline Bachelor degree & 312 & $49.84 \%$ \\
\hline Master degree & 178 & $28.43 \%$ \\
\hline Doctoral and advanced & 26 & $4.15 \%$ \\
\hline Students & Work status: & $13.41 \%$ \\
\hline Civil service & 84 & $2.06 \%$ \\
\hline Non-civil service & 13 & $36.74 \%$ \\
\hline Self-employed / business & 230 & $29.39 \%$ \\
\hline Retired & 184 & $6.07 \%$ \\
\hline Unemployed & 38 & 12.30 \\
\hline
\end{tabular}

Table-III: Frequency distribution of respondents by use of anti-infective agents

\begin{tabular}{|c|c|c|c|c|c|c|c|c|c|c|}
\hline & \multirow[b]{2}{*}{$\begin{array}{c}\text { Number of } \\
\text { Respondents }\end{array}$} & \multicolumn{2}{|c|}{ Azithromycin } & \multicolumn{2}{|c|}{ Doxycycline } & \multicolumn{2}{|c|}{ Hydroxychloroquin } & \multicolumn{2}{|c|}{ Ivermectin } \\
\hline & & & $\mathrm{N}$ & $\begin{array}{c}\text { Cost } \\
\text { involved } \\
\text { (USD) }\end{array}$ & $\mathrm{N}$ & $\begin{array}{c}\text { Cost } \\
\text { involved } \\
\text { (USD) }\end{array}$ & $\mathrm{N}$ & $\begin{array}{c}\text { Cost } \\
\text { involved } \\
\text { (USD) }\end{array}$ & $\mathrm{N}$ & $\begin{array}{c}\text { Cost } \\
\text { involved } \\
\text { (USD) }\end{array}$ \\
\hline \multirow{3}{*}{$\begin{array}{l}\text { RT- } \\
\text { PCR } \\
\text { test }\end{array}$} & Positive & 132 & 111 & 490 & 93 & 227 & 84 & 420 & 109 & 160 \\
\hline & Negative & 78 & 20 & 102 & 31 & 76 & 0 & 0 & 55 & 81 \\
\hline & Not done & 416 & 208 & 1046 & 128 & 313 & 44 & 215 & 319 & 190 \\
\hline \multicolumn{2}{|c|}{ Total } & 626 & 339 & 1638 & 252 & 616 & 128 & 635 & 483 & 710 \\
\hline
\end{tabular}

- $\quad$ Cost involved $=$ Unit price $\times$ Daily dosage $\times$ Number of days

- Total cost converted from local BDT to USD

Out of 626 respondents, only $73(11.66 \%)$ did not take any medication during the survey period as 12 (1.91\%) were negative by rRT-PCR test for COVID-19 and 61 (9.74\%) did not test. The remaining 132 respondents (21.08\%) was found positive test results for COVID-19.

The most frequently used prescription-only drug among the respondents were ivermectin (77.15\%), azithromycin (54.15\%), montelukast (43.13\%), calcium supplements (41.37\%), doxycycline (40.25\%), and hydroxychloroquine (20.44\%) respectively. The frequency of taking the prescription-only drugs among the respondents who were not even diagnosed by the rRT-PCR positive results, was reported higher with ivermectin (76.68\%) and azithromycin (50.0\%) as shown in Table-III. 


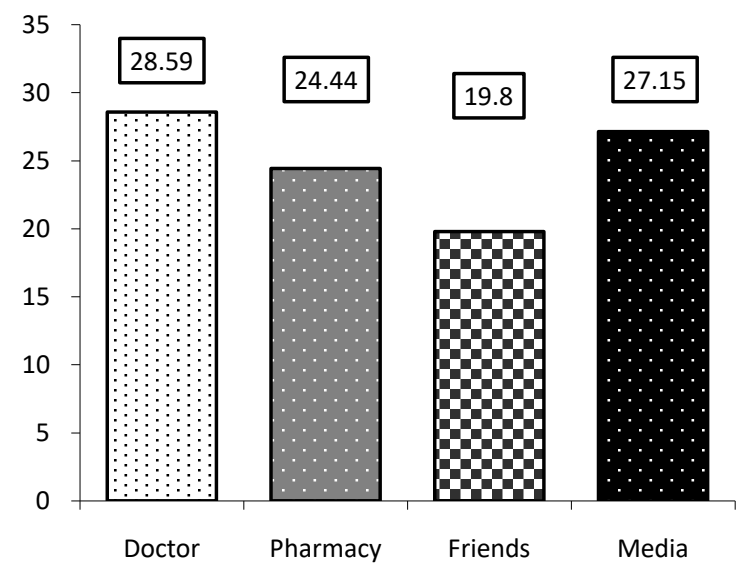

Figure-1: Distribution of respondents taken medication according to source of advices

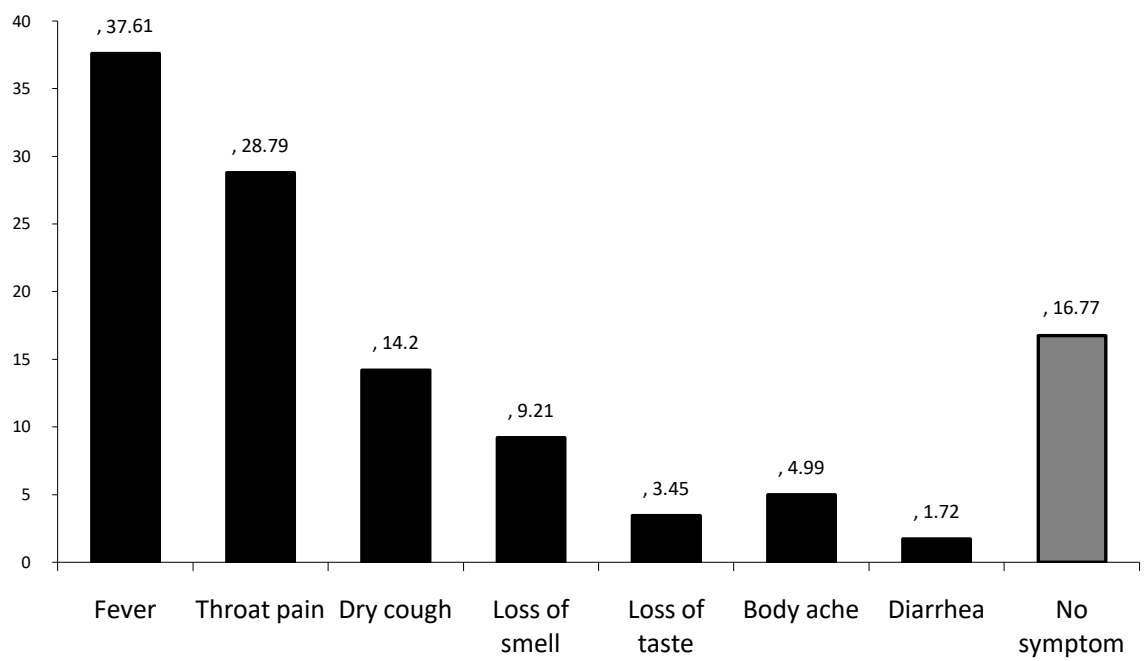

Figure-2: Distribution of respondents taken medication according to symptoms

Among the respondents, only 179 (28.59\%) took medication with doctors' advic and remaining 447 (71.40\%) respondents took the drugs, as "selfmedication" by the other sources like friends/family, pharmacy/dispensary and media/internet as shown in Fig-1.

A total of 105 (16.77\%) respondents took medications without having any symptoms, and the remaining 521 respondents, common symptoms for which the respondents took medications were fever (37.61\%), throat pain (28.79\%), dry-cough (14.20\%), loss of smell $(9.21 \%)$, loss of taste $(3.45 \%)$, body ache $(4.99 \%)$, and rarely diarrhea $(1.72 \%)$ respectively as shown in Fig-2. 


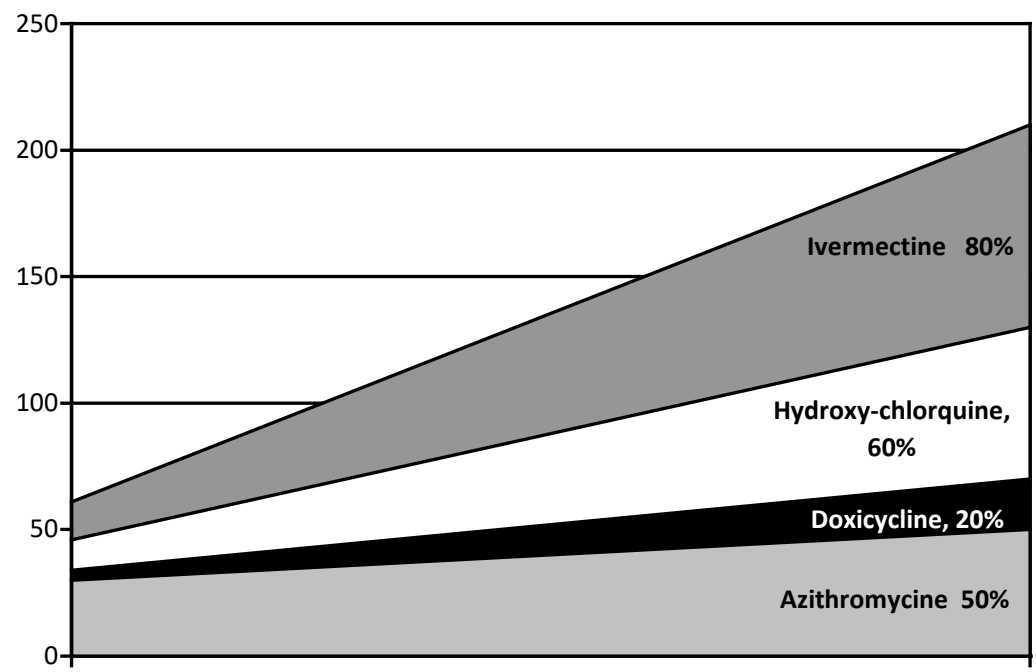

Figure-3: Raised price of the anti-infective agents during COVID-19 outbreak

The market price of the anti-infective agents was higher than the retail price as shown in Fig-3. Azithromycin raised almost 37\%, hydroxychlorquine $18 \%$, doxycycline $12 \%$ and ivermectin $7 \%$, respectively.

\section{Discussion}

To the best of our knowledge, this is the first online survey in Dhaka city evaluating the pattern and frequency of self-medication practice of prescriptiononly drugs in the COVID-19 outbreak (April to June 2020) in Bangladesh. As the survey population was welleducated adults from different working status, the respondents' participation was expected to represent the sincerest and accurate scenario of the defined survey population.

An almost equal proportion of males and females participated in the study and most of them (50.47\%) belonged to the age group of $45-54$ years. The highest number of respondents $(49.84 \%)$ were graduates (Bachelor's degree), and the lowest with doctoral degrees (4.15\%). Only $2.06 \%$ respondents were from civil service and the rest were from non-civil service (36.74\%), self-employed, or business (29.39\%) living in Dhaka city at the time of the COVID-19 pandemic.

Among 626 survey population in Dhaka city who had taken medication for COVID-19, only 132 (21.08\%) were documented as positive and $78(12.45 \%)$ as negative by RT-PCR test. The rest of 416 (66.45\%) had never done the test, but almost 355 (85.33\%) had taken medication without doing any test for the COVID-19. This finding could be due to having additional distress due to high self-awareness of their health, as reported by Roberts $T$. et al. among people with higher educational status $^{9}$. Having self-medication without detecting COVID-19 among a large number of respondents could also be due to feeling of insecurity influenced by the availability of local medical resources, efficiency of the public health system, and prevention and control measures taken in pandemic situation ${ }^{17}$.

The rate of self-medication of antimicrobial agents like azithromycin (54.15\%), doxycycline (40.25\%) was found much higher during the outbreak of COVID19 comparing to $21 \%$ and $25 \%$ for azithromycin and doxycycline before the pandemic as reported by Chowdhury $\mathrm{N}$ et $\mathrm{al}^{13}$. Azithromycin was the fifth-highest percentage of people with self-medication throughout the previous years, whereas it became the most common antibiotic during the present pandemic. On the other hand, ivermectin being the anti-parasitic agent, was self-medicated by $77.15 \%$ of the respondents. This might be due to the nationwide broadcast of an experience by a team of Bangladeshi physicians, and Bangladesh Medical College Hospital (BMCH) claimed as "outstanding results" in 60 patients with COVID-19 patients all of whom recovered in a combination with ivermectin and doxycycline ${ }^{12}$. This attempt was made on the outcome of an in-vitro study reported as a single treatment by ivermectin is capable of $\sim 5000$-fold reduction of viral load at 48 hours in cell culture ${ }^{14}$. Selfmedication of this drug was found highest (483/626) among the respondents irrespective of test results by RT-PCR. Though the drugs like chloroquine, hydroxychloroquine and azithromycin, was recommended in the treatment protocol of the Covid-19 patients in Bangladesh, according to the "National Guidelines on Clinical Management of Coronavirus Disease-2019" published in the health directorate's website $^{11}$; hydroxychloroquine was used much less $(20.44 \%)$ than any other antimicrobials without prescription. This could be due to mass publicity and sharing of news in national and international news and social media as the drug can cause hazardous abnormalities in cardiac rhythm in the COVID-19 patients, and should be limited only in clinical trials or hospitals with adequate facilities to monitor any cardiac 
complications, warned by FDA in a safety communication briefing globally ${ }^{12}$. The overall the prevalence and dominance of self- medication of antimicrobials in low and middle-income countries were reported around $39 \%$ in previous studies before the COVID-19 pandemic ${ }^{15,16}$ but was outrageously higher (88.33\%) in Dhaka city during the pandemic.

Considering the sources or advice for medication, only 179 (28.59\%) respondents followed or consulted with doctors and rest by media or internet (27.15\%), pharmacy or dispensary (24.44\%), and friends or family (19.8\%). This finding was very much similar to the previous studies that reported the high prevalence of self-medication (including antimicrobials) since people could obtain any drugs from the pharmacies without prescription even in the distant areas of the country ${ }^{18}$. Moreover, during a pandemic, people struggle to cope with constant news of the spread and effects of COVID19 on news-media, social-media, internet without having adequate forms of social support and access to doctors as a result of lockdowns and self-isolation ${ }^{8,19}$. Most of the respondents (37.61\%) took antibiotics as selfmedication for fever during Covid-19 outbreak, followed by throat pain $(28.79 \%)$, dry cough $(14.20 \%)$, whereas almost $16.77 \%$ respondents had no symptoms whatsoever. Having inappropriate antimicrobials, and supplementary medications (zinc, calcium, Vitamin-D) without prescription is associated with the risk of drug interactions, masking symptoms of underlying diseases, and most importantly, the development of antimicrobial resistance ${ }^{20,21}$

Prices of essential COVID-19 medicines have increased $4 \%$ globally since February 2020 , as reported by Gustav Ando in Life Science Research and Analysis. Although there is no specific treatment for Covid-19, the drug administration in Bangladesh started working in advance to increase the production of some supportive medicines ${ }^{22}$. Despite the availability of essential drugs, the increase demand in major cities for self-medication of azithromycin raised almost 37\%, hydroxychlorquine $18 \%$, doxycycline $12 \%$, and ivermectin $7 \%$ respectively. The total amount of buying those medicines in response to COVID-19 situation had an unnecessary financial burden on the people in Dhaka. Overall economic hardship in low and middle-income countries have to cope with the added expenditure that could be avoided by strict regulatory surveillance on self-medication and dispensing without prescription.

Although there is no approved specific medication to prevent or treat COVID-19, this online survey among the educated adults with high socioeconomic standings revealed that a high prevalence of self-medication of prescription-only drugs was persistent during the outbreak in Dhaka city. Unsolicited news of spread, effects and remedies in media channels, internet, mental stress of lockdown, and isolation, insecurity, and panic about the scarcity of drug and healthcare support might has triggered up the practice self-medication. Psychological distress levels were also influenced by availability of local medical resources, prevention and control measures ${ }^{23}$. There is sufficient evidence of increasing resistance to antibiotics in Bangladesh resulting from irrational and misuse of antibiotics, where sales of antibiotics are not restricted at any level ${ }^{24}$. Unopposed access to buy antibiotics and its injudicious use might provoke a long-term burden of drug-resistant strains with problems of under and overdosage, treatment failure and severe adverse effects on vital organs. It also results in delays in care seeking, which results in paradoxical economic loss due to delayed diagnosis, and irrational treatment ${ }^{25}$. Bangladesh is already in the burden of a lower ratio of healthcare workers and a supply support system, with a high rate of community-transmission of COVID-19 and requires effective and efficient enforcement of regulation against free display and sales of drugs without prescription and individuals duly authorized.

\section{Conclusion}

The pattern of medication, including selfmedication, is an important health indicator, which reflects the degree of supply utilization, and regulatory enforcement of healthcare services within a community. Immediate acceleration of health education campaigns, strict legislations on dispensing drugs and increasing the quality, and access to healthcare are the important interventions that might change the people's healthseeking behavior ${ }^{26}$. The pandemic situation of COVID-19 is likely to sustain for years and it will have a huge socioeconomic and psycho-social impact on people's lifestyle and behavior, as predicted by the WHO, and epidemiologists from different regions. Therefore, a vast nationwide survey and surveillance should be done on self-medication of the mass population to protect them from the potential risks, overuse shortage and irrational financial burden during the COVID-19 outbreak.

\section{ACKNOWLEDGEMENT}

We gratefully acknowledge all the respondents for their spontaneous participation in the study. We also extend our gratitude and thanks to Dr. Farhana Selina for data extraction, logistic and software support.

Funding: No fund or grants to declare.

Conflicts of Interest: None of the author or co-authors has any conflict of interest regarding any financial and personal relationships with other people or organizations that could inappropriately influence (bias) the work.

\section{References Références Referencias}

1. Oyediran $\mathrm{O}$, Ayandrian EO, Olatubi $\mathrm{Ml}$ et al. Awareness of risk associated with self-medication among patients attending out-patient department of 
a tertiary hospital in south western Nigeria. International Journal of Africa Nursing Science 2019; 10: 110-115.

2. WHO. Report of the WHO Expert Committee on National Drug Policies. Geneva, Ed: 1, 1995. Available at: https://apps.who.int/iris/handle/10665/ 63068? locale-attribute =en\&show = full

3. Hughes CM, McElnay JC, Fleming GF. Benefits and risks of self-medication. Drg Saf. 2001; 24:1027-37.

4. Hussain S, Malik F, Hameed A, Riaz H. Exploring health seeking behavior, medicine use and selfmedication in rural and urban Pakistan. Southern Med Rev. 2008; 3:32-34.

5. https://www.who.int/workforcealliance/countries/bgd len/

6. Report in Dhaka Tribune, July 21, 2019. Available at: https://www.dhakatribune.com/health/2019/07/21/

patient-doctors-nurses-ratio-bangladesh- lags- farbehind -its-neighbours

7. Nasir M, Zahan T, Parvin RA et al. Comaparative study on knowledge, attitude and practice of selfmedication among the medical and non-medical undergraduate students in Dhaka city. World Journal of Pharmaceuticals and Life Sciences 2017; 3(4): 17-20.

8. Kretchy IA, Asiedu-Danso M, Kretchy JP. Medication management and adherence during the COVID-19 pandemic: Perspectives and experiences from lowand middle-income countries. Research in Social and Administrative Pharmacy. Available at: https://www.sciencedirect.com/science/article/pii/ S1551741120303326 [IN PRESS]

9. Roberts T, Miguel Esponda G, Krupchanka D, et al. Factors associated with health service utilizationfor common mental disorders: a systematic review. BMC Psychiatry 2018; 18:262.

10. WHO. Available at: https://www.who.int/docs/ default-source/searo/bangladesh/covid-19-whobangladesh-situation-reports/who-covid-19-update18-20200629.pdf?sfvrsn=6ef8ba08_2

11. National Guidelines on Clinical Management of Coronavirus Disease 2019 (Covid-19), by Disease Control Division, Directorate General of Health Services Ministry of Health \& Family Welfare; Government of the People's Republic of Bangladesh. Version-4, 30 March, 2020. Available at: https://dghs.gov.bd/index.php/en/home/5343covid-19-update

12. News Report, available at: https://thelogicalindian. com/story-feed/awareness/selfmedication-

coronavirus-covid-19-pandemic-20327

13. Chowdhury N, Islam MR, Hasan MM, et al. International Journal of Pharmacy Teaching \& Practices. 2013; 4(1):504-510.

14. LeonCaly, Julian D.Druce, Mike G.Catton, et al. The FDA-approved drug ivermectin inhibits the replication of SARS-CoV-2 in vitro. Antiviral Research. 2020; 178: 104787.

15. Ocan M, Obuku EA, Bwanga F, et al. Household antimicrobial self-medication: a systematic review and meta-analysis of the burden, risk factors and outcomes in developing countries. BMC Public Health. 2015; 15:742.

16. Morgan DJ, Okeke IN, Laxminarayan R, et al. Nonprescription antimicrobial use worldwide: A systematic review. Lancet Infect Dis. 2011; 11: 692-701.

17. Wind TR, Komproe $\mathbb{H}$. The mechanism that associate community social capital with postdisaster mental health: a multilevel model. Soc Sci Med 2012; 75: 1715-20.

18. Islam MS. Self-medications among higher educated population in Bangladesh: an email-based exploratory study. Internet J Health 2007; 5: 2.

19. Huibo Li, Siqian Zheng, Fang Liu, et al. Fighting against COVID-19: Innovative strategies for clinical pharmacists. Res Soc Adm Pharm 2020; [IN PRESS] Available at: https://www.sciencedirect. com/science/article/pii/S1551741120303284

20. Okeke IN, Klugman KP, Bhutta ZA. Antimicrobial resistance in developing countries Part II: strategies for containment. Lancet Infect Dis. 2005; 5: 568-80.

21. World Health Organization. Community-Based Surveillance of Antimicrobial use and Resistance in Resource constrained settings. A report on five pilot projects. Geneva, Switzerland: WHO; 2009. Available at: http//www.apps.who.int/medicinedocs /documents/s16168e.pdf.

22. DGDA-Medicine supply, prices managed well amid crisis. The daily Star; May08, 2020 at https://www.thedailystar.net/frontpage/news/medici ne-supply-prices-managed-well-amid-crisis1900585 Viewed on: 30 July, 2020.

23. Qiu J, Shen B, Zhao M, et al. A nationwide survey of psychological distress among Chinese people in the COVID-19 epidemic: implications and policy recommendations. General Psychiatry. 2020; 33: e100213.

24. Biswas M, Roy MN, Manik IN, et al. Self-medicated antibiotics in Bangladesh: a cross sectional health survey conducted in the Rajshahi city. BMC Public Health 2014; 14: 847.

25. Kalyan VS, Sudhakar K, Srinivas $P$, et al. Evaluation of self-medication practices among undergraduate dental students of tertiary care teaching dental hospital in south India. Journal of Education and Ethics in Dentistry 2013; 3(1):21-25.

26. Alghanim, SA. Self-medication practice among patients in a public health care system. Eastern Mediterranean Health Journal 2011; 7(5): 409-416. 